\title{
MÕNEST VÄRVINIMETUSEST JA NENDE TÄHENDUSVAHEKORDADEST EESTI JA SOOME KEELES
}

\section{Vilja Oja, Mari Uusküla}

\begin{abstract}
Ülevaade. Artiklis analüüsitakse lilla-roosa värvigamma nimetusi eesti ja soome suulises keeles. Käsitletav murdeaines kajastab peamiselt 20. saj 1. poole keelt ning tänapäevaste nimetustena arvestatakse 1990ndatel ja 2005-2006. a läbi viidud küsitluste tulemusi. Lillat ja roosat värvi on eesti ja soome keeles tähistatud põhivärvi (sinist või punast) märkiva sõnaga ja nendest moodustatud ühenditega, samuti võrdlusest lähtuvate liitnimetustega. Nende kõrval esineb rida indoeuroopa tüvedega laentermineid, nagu lilla, violett, maliina, aniliin, purpur, kretliini, roosa ja pinkki. Keelejuhtide ütluste põhjal on määratletud värvigamma osa või konkreetne toon, mida mingi nimetusega väljendatakse. Selgus, et indoeuroopa keelest laenatud terminite kasutus erineb ühelt poolt laenuandja keele omast ning teiselt poolt keeliti/ murdeti läänemeresoome alal. Sõnavara võrdlus näitas ühtlasi viimase saja aasta jooksul nende värvimõistete nimetamises toimunud muutusi. Muuhulgas ilmnes selgelt tendents laennimetuste järjest suuremale eelistusele.*
\end{abstract}

Võtmesõnad: värvinimetused, roosa, lilla, kõnekeel, murdekeel, eesti keel, soome keel

\section{Sissejuhatuseks}

Kas kanarbikuõied on roosad või lillad? Mis värvi on nõmmeliivatee? Kuidas tõlkida sirelililla inglise keelde? Missugust värvust väljendab roosa eesti ja missugust soome keeles? Need ja paljud sarnased küsimused tekivad sageli tõlketöös ja keeleõppes, samuti neil, kel vaja värve või värvilisi objekte (nt lilled, tekstiilesemed) kirjeldada. See ajendas käesoleva kirjutise autoreid lähemalt uurima lilla-roosa värvigamma nimetuste vahekordi kahes suurimas läänemeresoome keeles.

* Uurimistöö on valminud Eesti Keele Instituudi baasfinantseerimise ning Eesti Teadusfondi grantide nr 6744 ja 7717 
Lähtematerjaliks on ühelt poolt tänapäeva suuline eesti ja soome keel ning teiselt poolt varasem, 20. sajandil kogutud murdeaines mõlemast keelest. Tänapäeva eesti keele värvinimetuste osas on aluseks võetud Urmas Sutropi 1990-ndatel aastatel Tallinnas ja Tartus läbi viidud küsitluste tulemused ning soome värvinimetuste osas 2005ja 2006. a Helsingis, Espoos, Tuusulas, Turus, ja Lempääläs Mari Uusküla küsitlustele saadud vastused. Mõlemad küsitlejad töötasid Ian Daviese ja Greville Corbett' välimeetodil (1995: 27-28), eesmärgiks oli välja selgitada vastava keele põhivärvinimed (vt Sutrop 1995: 798-799, 2002: 58-59, Uusküla 2008: 30-31). Esmalt paluti keelejuhtidel vabalt loetleda nii palju värvinimetusi, kui neile meenus, seejärel näidati ükshaaval 65 värvitahvlit ning lasti nimetada iga konkreetset värvi. See meetod võimaldab küllalt täpselt määrata värvinimetuste sisu ning eri keelte nimetusi omavahel võrrelda.

Suur osa käsitletavast eesti murrete materjalist pärineb Tallinnas Eesti Keele Instituudis koostatud eesti murdesõnavara koondkartoteegist ning soome murdeaines Helsingis Kotimaisten kielten tutkimuskeskuses säilitatavast soome murdesõnavara arhiivist. Nendes murdekogudes talletatud sõnavara kajastab valdavalt 20. sajandi 1. poole suulist keelesituatsiooni (hiljem kogutud materjalide puhul on keelejuhtideks valitud eranditult vana murde kõnelejad). Murdekogudest saadud värvinimetuste semantika määratlemisel on aluseks võetud ühelt poolt sõna kasutus näitelausetes ja -fraasides ning keelejuhi selgitused, teiselt poolt koguja kommentaarid. Murdenäited on artiklis edasi antud kirjakeele vahenditega, lisatud on üksnes palatalisatsioonimärk konsonandi kohal või kõrval (nt ń, $l^{\prime}$ ).

Lilla ja roosa värvi eesti- ja soomekeelsed nimetused võib laias laastus liigitada kahte rühma: omasõnavara ja laenatud terminid. Järgnevalt käsitletakse kummagi rühma sõnavara eraldi, kuid pööratakse erilist tähelepanu nimetuste omavahelistele suhetele ning nende tähendusnüansside sarnasustele ja erinevustele.

\section{Omasõnavara}

Omasõnavaraks on siin arvatud lilla ja roosa nimetused, millel vastavalt eesti või soome keeles on olemas muu varasem otstarve, nagu põhivärve (sinist ja punast) märkivad sõnad ja nende baasil moodustatud ühendid (vt 2.1). Siia kuuluvad ka nn kirjeldavad ühendid, mis vahendavad teavet värvi kohta võrdluse teel ehk võrdlusel baseeruvad värvinimetused (vt 2.2).

\subsection{Põhivärvidest lähtuvad nimetused}

Eesti ja soome keeles on tavaline väljendada kahe värvi segatoone põhivärvide nimedest moodustatud liitsõnaga. Lillat märgivad kahe värvinimetuse kombinatsioonid, nagu eesti sinakaspunane, (Vastseliina) sinineverrev jt, soome sinipunainen, murdeis sinisempunane, sinipunerva, punasesinertävä, punasininen, liusunpunainen (liusu 'sinine') jms. Soome kirjakeeles on tänini lilla värvi nimena enim soositud liitsõna sinipunainen ( $<$ sininen + punainen) ja roosa värvi nimena vaaleanpunainen (< vaalea 'hele' + punainen) (vt nt Kerttula 2007: 160, Uusküla 2007: 383 jj). Viimasega sarnaneb lõunaeesti murdeline val'ssverrev < val'ss 
'hele' + verrev 'punane' (vt Oja 2001: 66-67). Soome liitsõna vaaleanpunainen on sedavõrd üldine roosa värvi nimetus, et sellest on omakorda moodustatud ühendid tummanvaaleanpunainen 'tumeroosa' ja vaaleanvaaleanpunainen 'heleroosa' (vt Uusküla 2009: 270). Värvinime sinipunainen kasutus kõnekeeles on sel sajandil tunduvalt vähenenud ning lillat värvi on hakatud tähistama laenterminitega.

Sageli on lillat või roosat värvi nimetatud vaid ühe - emma-kumma põhivärvi järgi, näiteks lillakasroosa kartulisordi kohta on eestlased öelnud nii sinine kui punane (lõunaeesti keeles ka verev). Murdeaines näitab, et lillat seostatakse pigem sinise kui punase värviga, nt eesti (Muhu) siniõllud 'jaanililled' o sinised; (Käina) viiolett on sinine; (Karuse) sinised kaapsad 'punased kapsad' olid mõisates; (Leivu) šinnin eirelääts 'lilla hiirehernes', šinnin upinain 'punane ristik'; (Torma) sinine ja lilla on ühe näu pial; soome (Ylikiiminki, Paavola) liusi = sinipunainen. Roosat värvi väljendatakse ka punase värvi moderatiivse nimetusega, nagu soome punertava 'punakas', lõunaeesti verkjass id.

\subsection{Võrdlusel baseeruvad värvinimetused}

Eelmistest täpsema värvitooni määratluse annavad liitnimetused, mille nimisõnaline täiendosa tähistab üldtuntud värvusega võrdlusalust. Sellise ühendi põhisõna on kas värvinimetus või pelgalt parameetersõna, mis osutab, et tegemist on värviga.

Värvinimetus on põhisõnaks sellistes igapäevastes lillat väljendavais liitsõnades nagu eesti peedipunane, kannikesesinine, soome orvokinsininen (< orvokki 'kannike' + sininen) jt. Roosa värvi nimetustest kuuluvad siia näiteks eestivaarikapunane ja soome ruusunpunainen, sõnasõnalises tõlkes 'roosi (= kibuvitsa)' + 'punane'. Põhisõnana esinevad loomulikult ka lillat ja roosat tähistavad laenulised värvinimetused (nt sirelililla), kuid neid käsitletakse allpool vastava põhisõna juures.

Parameetersõna ühendeist on ehk tuntuim eesti sirelikarva, soome sireeninvärinen (sireeni 'sirel' + värinen 'värvi'). Sama konstruktsiooniga on Setu murraku roosa värvi nimetus maŕańäolinõ (sõnasõnalt 'marja välimusega' ehk 'marja värvi'), kusjuures ühendit muśtjanõ maŕanäolinõ (muśtjanõ 'tume') on setud kasutanud tähenduses 'lilla'. Mõnikord on murdekeeles värvust iseloomustatud ka võrdluse alusel nimisõnast moodustatud omadussõnatuletisega, nt (Kodavere) kirsikäs 'roosa'.

\section{Laenatud terminid}

Lisaks eelkirjeldatud sõnadele väljendatakse mõlemas kõnealuses keeles lillat ning roosat indoeuroopa keelest laenatud terminitega. Eesti keeles on niisugused laennimetused lilla, violett, maliina, aniliin, purpur ja roosa, soome keeles liila, violetti, kretliini, aniliini, purppura, roosa ja pinkki. Ehkki mitu samatüvelist sõna esineb nii eesti kui ka soome keeles, ei kasutata neid alati keeliti/murdeti ühtmoodi. 


\subsection{Lilla}

Eesti keelele kõige omasem lilla värvi nimetus on saksa laensõna lilla (< sks lila 'lilla') (Mägiste 1982-1983: 1312). Nii tänapäeva keeles kui ka eelmise sajandi murdekõnes on selle sõnaga väljendatud igasuguste heledus-tumedus- ja kirkusastmetega ning eri toonides sinise ja punase segavärvust. Sõnaga lilla (Muhu murrakus lille) kirjeldatakse mitmesuguste taimede õite värvust (nt kanarbik, jaanilill, priimula, ohakas, naistenõges, hiirehernes, kurereha, sirel, palderjan, kellukad), aga ka palju muud (nt riie, lõng, kaaliumpermanganaat, taevas, lepaseened, kartulid, marjad). Eesti keeles märgib sõna lilla niivõrd laia värviskaalat, et erinevate toonide ning heledus-tumedusastmete täpsustamiseks kasutatakse tihti liitsõnu, nt tumelilla, helelilla, kahvatulilla, erelilla, sügavlilla, erklilla, punakaslilla, sinakaslilla, mustjaslilla, valkjaslilla; (Iisaku rannikumurdes) vaalakaslilla; (Juuru) kaks lillat värvi: teene punalilla, teene sinililla värv; (Karksi) vanast õigati värmi lilla sinine, lilla punane.

Soome keeles päris sama kujuga omadussõna pole. Nimisõna lilla märgib soome murdeis küpset soomurakat ning sellest võrdluse alusel moodustatud liitsõna lillapunane on kasutatud lillakaspunase värvi nimetusena, nt (Kivennapa) lillanpunane = punavioletti, sinipunanen; siniseen vivahtava punanen kutsuttiin lillapunaseksi.

Tänapäeva soome keelde on rootsi keelest laenatud adjektiiv lila või liila $(<$ rts lila 'lilla'), mis väljendab tavaliselt sirelikarva helelillat värvust. Samas tähenduses esineb liitsõna liilanvärinen. Ehkki eesti lilla ja soome li(i)la on laenatud eri keelte kaudu, pärinevad need samast algtüvest: < < pr lilas (< lilac) 'sirel' < hisp lilac < ar līlāc id. < pärsia lìlac nīlak 'sinakas' < nīl 'sinine, indigo' (SSA 2: 73). Tänapäeva soome kõnekeeles on eriti nooremal põlvkonnal levinud lïla enam kui violetti, kuigi esimese värv on heledam, teisel tumedam. Samas kasutatakse kahte laenterminit ka sünonüümselt. Eesti lilla sisuliseks vasteks on soome keeles tavaliselt kahest värvisõnast koosnev liitnimetus sinipunainen, paljudes murretes kretliini vms. Seega ei ole eesti lilla ja soome li(i)la sünonüümid. Kui soome sõna ingliskeelne vaste on lilac, siis eesti keelde võiks selle tõlkida liitsõnadega helelilla või sirelililla ning üldnimetuse lilla ingliskeelseks vasteks sobib kõige paremini purple (vt Oja 2002: 256-258).

\subsection{Violett}

Romaani algupäraga lillenimest tekkinud värvisõna (vrd pr violette 'kannike; lilla' < ld viola 'kannike; lilla') märgib punase ja sinise segavärvi nii eesti kui ka soome keeles. Eesti keelde on violett laenatud saksa keele kaudu (< sks subst Violett; adj violett), soomekeelne violetti on saadud rootsi keele vahendusel ( $<$ rts violett 'violetne') (Mägiste 1982-1983: 3870, SSA 3: 454). Murdekeeles on värvinimetuse levila üsna ulatuslik. Laensõnale omaselt esineb mõlemas keeles rohkesti erinevaid häälikulisi variante. Eestlased on võõrapärase nimetuse rahvakeeles sageli asendanud tuttava sõnaga viiul viiuldi või mõne muu mugandatud variandiga (vt nt Oja 2001: 29, 2007: 205). Kirjakeelset sõnakuju violet( $t$ ) on kuuldud vaid paaril korral uuemas murdekeeles. Soome murdesõnades varieerub alguskonsonant: $v-/ f$ - ja 1. silbi diftongi järelosis, labiaalvokaal: -io-/-iu-/-iü-. 
Eesti murretes esineb sõna peamiselt substantiivsena - lilla värvaine ja roosa kartulisordi nimetusena (nt vïuli väŕv; viüuliti kardula, viüuletid) ning adjektiivsena iseloomustab kõige sagedamini nendesamade objektide värvust. Murdekõnelejate jutus on selgesti tajutav asjaolu, et algselt on eesti keelde laenatud substantiiv Lääne-Euroopast toodud värvaine nimetus. Puutaolise vormi järgi nimetati värvaine tükki: viiulipuu, viiuldi puu, viioliti värvi puu vms (Oja 2007: 204). Hiljem on lisandunud adjektiivne funktsioon - sama sõnaga on hakatud nimetama ka selle aine värvust ja sellega värvimisel saadud punase-sinise vahelist värvitooni. Näiteks Rannu murraku keelejuht väidab, et lõnga sai violetiks värvida üksnes vabrikuvärviga: vïuli sinine ol'li poodi värm, ega seräst mõtsa värmega es saa tetä.

Soome murretes on adjektiivset kasutust rohkem. Mõlemas keeles tarvitatakse ka ne/nen-sufiksiga adjektiive ning liitnimetusi, mille põhisõnaks sinist või punast värvi märkiv adjektiiv: nt eesti violetne, viioletisinine, viiulipunane jt, soome violettinen, violettisininen, violetin sininen, violettipunainen jt. Tänapäeva soome keeles on violetti kujunenud peamiseks lilla värvi nimetuseks ning suhteliselt uus laen liila või lila on selle hüponüüm (Kerttula 2007: 159-160). Eesti keeles on violett ning violetne praeguseks samuti saanud üldkasutatavaiks värvisõnadeks. Ometi näitab Sutropi kogutud materjal, et sõna violett on kõnekeeles oluliselt harvem kasutatav kui lilla, kuigi esineb lilla sünonüümina (2002: 74 jj).

\subsection{Kretliini}

Soome kõnekeeles ja paljudes murretes märgib lillat värvust rootsi laen kretliini < rts gredelin, gredlin < pr gris de line 'linakarva hall' (Hellquist 1922: 199, SSA 1: 418; vt ka Koski 1983: 230-231). Värvinimetus retelijini esines juba 18. saj soome keeles (vt Ganander 1997: 785). 20. saj murdekeeles oli sõna laialt levinud, vähem näiteid on siiski registreeritud Kesk-Soome murdest ja Põhja-Soomest ning ühtki teadet pole ingeri murdeist. Häälikulisi murdevariante on laensõnale omaselt rohkesti: krätliini, kreteliini, reliini, retlinki, krekliini, prekliini jt, lisaks adjektiivisufiksiga tuletised $(k)$ retliininen ja retuliininen. Laensõna esineb nii ühendis parameetersõnaga (nt retliininkarvaine, retliinivärinen) kui ka punase ning sinise värvi nimetustega (nt kretliinisininen, retliininpunainen). Sagedamini kirjeldatakse nõnda värvitud esemeid, peamiselt lõnga või riiet, aga ka muude objektide, näiteks kanarbiku, kartuli, hortensia ja varesemarja õite lillat või lillakasroosat värvust. Sünonüümina on enim mainitud liitnimetust sinipunainen, kuid ka sõnu punasininen, violetti, violetin punainen jm. Samas on laensõna eelistatud isegi omapärasele liitnimetusele, käsitades viimast vaid kirjeldava seletusena, kusjuures tõeline värvinimi on kretliini, nt (Laitila) sinipunase färine on kretliini. Mõned keelejuhid on 1930-ndail aastail väitnud, et sõna on tema kodumurdes vananenud. Käesoleval sajandil läbi viidud küsitlus näitas, et mõne vanema keelejuhi idiolekti kuulub endiselt sõna retliini, retuliini vms, mis märgib tumedamat või sinakaslillat värvust. Olulisi piirkondlikke erinevusi sõna kasutajaskonnas ei täheldatud (Uusküla 2009: 270). Tänapäeva soome keele sõnaraamatuist leiame märksõnad gredliini (kõnekeeles kretliini) (NS 1: 308) ja kretliini märgendiga "vananenud“ (PS 1: 555). Soome murrete sõnaraamatu tegijad on otsustanud sõnavariandid koondada märksõna retliini alla. 


\subsection{Liina}

Eesti läänemurde alal on kellukate, kanarbiku jt lillade ning roosade õite värvi kirjeldatud adjektiiviga liina või liine. Kahtlemata on tegemist lühenenud sõnakujudega, ent pole päris selge, millisest laensõnast need on tulenenud. Mauno Koski oletus, et liina ja liine võiksid olla lühendused rootsi lilla värvi nimetusest gredlin (1983: 235) tundub ebausutavana, kuna rootsi sõna äratuntavaid variante pole eesti murretes registreeritud.

Mari Must on need sõnad ühitanud vene laenuga maliina (murdeis ka maliine, maleena) < vn малина 'vaarikas; vaarikapunane' (2000: 191). Ei ole aga võimatu, et liina ja liine on mugandused hoopis sõnast aniliin. Eesti keelde värvaine nimena laenatud võõrsõnal on rahvakeeles palju variante, nagu aneliin, aaniliin, aanilin(e), anililla jt. Soome 20. saj murdekeeles märkis aniliini (aneli, aliini jms variandid) samuti eelkõige värvainet, harvem värvust. Adjektiivi funktsiooni täitis sageli liitnimetus, nagu eesti (Kanepi) aanilin verev, (Urvaste) anilillisinine, soome aneliinipunainen, annelipunanen, anoliinivärine jms.

Aniliinvärviga värviti lõnga lillaka varjundiga erkroosaks või lillakaspunaseks. Seetõttu on mõistetav, miks eesti murdekõnelejail kipuvad võõrad sõnad aniliin ja maliina omavahel segunema, nt (Kadrina) maliina on ikke tema õige nimi, aneliiniks aga üiti. Mõlemad laenud esinevad ka 19. saj eesti murdekeelt kajastavas Wiedemanni sõnaraamatus (1973: 34 ja 580). Samasugust värvi väljendavad soome adjektiivid aneliinipunainen, eesti anililla, liina, maliina jt variandid, nt soome (Hailuoto) Anellia oli pahaa muuttumaan. Punasen sinistä väriltä, kulkukauppiaat möijät väriä 'Aniliin ei vahetanud kergelt värvi. Värvilt lilla, rändkaupmehed müüsid värvi'. Uusküla 2005-2006. a välitöödel selgus, et värvisõna aniliini ja ühend aniliinipunainen või aniliininpunainen väljendavad erkroosat ning lillakaspunast värvi nii noortel kui ka vanematel Soome eri paigust pärit inimestel (nimetust mainisid 17-52-aastased inimesed).

\subsection{Purpur}

Eesti purpur, purpurne, purpurpunane ja soome purppura, purppuranpunainen pärinevad tõenäoliselt Piiblist. Sama nimetust kandis tööstuslikult toodetud värvaine. Võimalik, et Piibli tõlgetesse tuli värvinimetus otse ladina keelest $(<\mathrm{ld}$ purpura), kuid eesti keelde võib sõna olla laenatud ka saksa või alamsaksa keele kaudu, vrd sks Purpur, asks purpur, ja soome keelde rootsi keele vahendusel, vrd rts purpur (Mägiste 1982-1983: 2241, SSA 2: 437).

Eesti ja soome rahvakeeles teatakse võõrsõna enamasti tähendustes 'punane' ja 'erepunane'. Mõned keelejuhid on kinnitanud, et purpur / purppuranpunainen on 'tumepunane' ja üksikud isikud on väitnud, et '(tume) lillakaspunane' (Kerttula 2007: 160, Oja 2001: 162-163). Käesoleval sajandil Soomes läbi viidud küsitlusel kasutasid värvinime purppura samuti vaid üksikud keelejuhid tähenduses 'punakaslilla', liitsõna purppuranpunainen viitas aga tavaliselt tumepunasele, punasele või lillakaspunasele värvitoonile. Üks katseisik kasutas ka liitsõnalist kombinatsiooni purppuravioletti tähenduses 'punakaslilla'. Nende adjektiividega on kirjeldatud näiteks punetavat taevast ja pilvi, loojuva päikese ja tulekahju kuma, vere värvi, lilleõite, lõnga ja riide värvi. 
"Eesti kirjakeele seletussõnaraamatus" (EKSS 4: 484) on värvinimetuse tähenduseks märgitud 'lillakaspunane', soome keele sõnaraamatuis 'lilla või sinise helgiga punane värv' (NS 4: 496, PS 2: 553). Mõnikord on ingliskeelse värvisõna purple eestikeelseks vasteks pakutud 'purpurne'. Sellisest tõlkest on soovitatav hoiduda, kuna see ei anna edasi õiget värvitooni. Parim eestikeelne tähendusvaste inglise omadussõnale purple on lilla (vt 2.1.).

\subsection{Roosa}

Eesti kirjakeeles ja kõigis murretes on roosa värvi üldnimetus sakslastelt laenatud omadussõna roosa (< sks rosa) ning rohkesti leidub ka sellise põhisõnaga liitvärvinimetusi, nagu heleroosa, haleroosa, (Iisaku rannikumurdes) vaalakas roosa, tumeroosa, vanaroosa, erkroosa, lillakasroosa jt. Murdekeeles on kasutatud ka adjektiivisufiksiga tuletisi roosane või roosaline. Wiedemanni sõnaraamat (1973: 979) näitab, et 19. saj keskpaiku oli see värvisõna eesti keeles kodunenud.

Soome keeles on roosa (< rts rosa 'roosa') sedavõrd uus, et 20. saj keskel ilmunud "Nykysuomen sanakirja" (NS) seda veel ei tunnista, kuid sajandi lõpul ilmunud "Suomen kielen perussanakirja" esitab sõna koos seletusega (vaalean) ruusunpunainen (PS 2: 665). Mõlemas keeles esineb sõna üksnes värvinimetusena, kuna taime (roosi ehk kibuvitsa) tähistab varasem laen (ee roos, sm ruusu). Erinevalt eesti keelest on tänapäeva soome keeles suhteliselt uus värvinimetus roosa nn moesõna, mis on paljudele tuttavaks saanud Soomes suurt populaarsust pälvinud kataloogikaubandusest (Koski 1983: 241-244, Uusküla 2009: 268-269). Aastail 2005-2006 Soomes küsitletud 68-st keelejuhist kasutas sõna roosa ligi 11\%, tähistades sellega erinevaid värvitoone (beež, kahvaturoosa, lõheroosa, hallikasroosa).

Eesti keeles väljendatakse sõnaga roosa ning selle tuletistega valge ja punase segavärvust, aga ka lillakasroosat ja kahvatulillat värvust. Nii roosa kui lillana on kirjeldatud näiteks kanarbiku, jaanilille ja sireli õisi ning punaka koorega kartuleid. Võrreldes omavahel kahes keeles sama sõnaga väljendatud värvusi, näeme, et soome roosa märgib kas hallikamat ja kahvatumat, või hoopis oranžikamat tooni kui eesti roosa ning seega ei ole eesti ja soome roosa täissünonüümid.

\subsection{Pinkki}

Tänapäeva soome keeles kasutatakse roosa värvi tähistamiseks teistki uut laensõna pinkki <<ingl pink (Kerttula 2007: 160, SSA 2: 368). Sõna on soome keeles levinud kõigepealt kaubandusliku terminina, märkides värvide ja mitmesuguste esemete värvust (Koski 1983: 241-244). Nagu roosa, on ka pinkki soome keeles omaks võetud alles 20. saj lõpul ning esineb kirjakeele sõnaraamatus tähendusseletusega vaalean neilikanpunainen, sõna-sõnalt 'nelgi värvi roosa' (PS 2: 477). Väga olulisi tähenduslikke erinevusi soome värvinimetuste pinkki ja roosa vahel möödunud sajandi keeles ei täheldatud (Kornerup, Wanscher 1961: 214). Sel sajandil tehtud küsitluste põhjal võib järeldada, et olukord on muutunud. Esiteks on omadussõna pinkki laiemalt levinud kui roosa, kuuludes suurema hulga inimeste idiolekti. Teiseks väljendatakse värvisõnaga pinkki väga konkreetset lillakasroosat tooni 
(vrd nurmnelgi, Dianthus deltoides õite värviga). Nooremate soomlaste kõnes on see tavaline omadussõna, esinedes ka liitsõna osana, nt tummanpinkki ja vaaleanpinkki (Uusküla 2009: 269-270). Kuidas seda värvi võõrkeeltes nimetada nii, et säiliks õige tähendus, peab iga tõlkija konkreetse teksti puhul otsustama.

\section{Kokkuvõtteks}

Asjaolu, et lilla värv sisaldab spektri kaht põhivärvi, kajastub otsesõnu liitnimetustes nagu eesti punakassinine, soome sinipunainen jms. Teiselt poolt soovivad inimesed nimetusega ka segavärvi domineerivat värvust edasi anda. Lillat ja roosat tähistavaid sõnu on püütud tähenduslikult diferentseerida ühelt poolt täiendava omadussõna abil (nt eesti punakaslilla, soome vaaleanpunainen), teiselt poolt võrdlusega (nt ee lõheroosa, sm sireeninvärinen).

Eesti keeles on kõige üldisema sisu ja kasutajaskonnaga laennimetused lilla ja roosa. Praeguseks on ka violett ning violetne saanud üldkasutatavaiks värvisõnadeks ning neid võib lugeda lilla sünonüümideks. Kõnekeeles eelistatakse siiski nimetust lilla. Soome keeles on violetti kujunenud peamiseks lilla värvi nimetuseks ning suhteliselt uus laen liila või lila on selle hüponüüm. Nooremad kõnelejad kasutavad aga omadussõna liila rohkem, kusjuures see tähistab varasemast laiemat spektriala. Eesti murretes märgivad violett ja selle variandid pigem värvainet, sellega võrreldes on soome murretes adjektiivset kasutust rohkem. 20. sajandi alguses ütlesid paljud soomlased kõigi sinise ja punase vahele jäävate toonide kohta kretliini või sinipunainen. Tänapäeval on nende omadussõnade kasutus vähenenud, noorte kõnepruugis võivad sõnad üldse puududa. Roosa värvi nimetusena on eesti keeles üldlevinud laensõna roosa, soome keeles käibib seni omakeelne liitnimetus vaaleanpunainen, mille kõrvale on siiski tekkinud uued laensõnad roosa ja pinkki.

Võrreldes kahes keeles sama sõnaga väljendatud värvusi omavahel, näeme, et soome roosa märgib kas hallikamat ja kahvatumat, või hoopis oranžikamat tooni kui eesti roosa ning seega ei ole eesti ja soome roosa täissünonüümid. Ka eesti lilla ja soome li(i)la ei ole enamasti sünonüümid. Soome murretes on eesti lilla vasteks tavaliselt kahest värvisõnast koosnev liitnimetus sinipunainen või laensõna kretliini variandid. Uus laen liila märgib tänapäeva soome keeles helelillat värvust, mille kohta eestlased ütlevad helelilla või sirelitilla. Selle ingliskeelne vaste on lilac, kui eesti lilla ingliskeelseks vasteks sobib kõige paremini purple. Üks oluline põhjus, miks samast algtüvest lähtunud laennimetusi kasutatakse eesti ja soome keeles erinevalt, on kindlasti erinev laenuallikas - eesti keelde tuli enamik neist sõnadest saksa keele kaudu, soome keelde aga rootsi keele vahendusel. Oma mõju avaldab ka laenamise aeg ehk laenu vanus.

Teine osa käsitletud laensõnu esineb mõlemas keeles enam-vähem samas tähenduses. Värvaine aniliin nime on murdekõnelejad mitut viisi mugandanud, sealhulgas esinevad rahvaetümoloogiast ajendatud variandid eesti anililla (hani + lilla), soome anneli jt. Mõlemas keeles tähistatakse nendega erkroosat ning lillakaspunast värvi. Laensõnu purpur jt samast tüvest tulenenud sõnu on enamik eestlasi ja soomlasi pidanud erepunase värvi nimetuseks. Ehkki mõlema keele sõnaraamatud annavad tähenduseks ka 'lillakaspunane', ei ole see läänemeresoomlaste keelepruugis inglise purple vaste. 
Roosa ja lilla värvi kokkupuutepunkte värviskaalal tähistavad ühelt poolt eesti liina, maliina, aniliin ja soome aniliini, pinkki. Teiselt poolt märgivad mõned värvisõnad niivõrd laia värviskaalat, et sama värvi kohta on kasutatud nii roosa kui ka lilla värvi nimetusi, nt eesti lilla ja roosa. Uurimuse tulemustele toetudes on tabelis 1 välja toodud soovituslikud eestikeelsed tähendusvasted soomekeelsetele lilla ja roosa värvi nimetustele.

Tabel 1. Soome sõnade soovituslikke tähendusvasteid tänapäeva eesti keeles

\begin{tabular}{|l|l|}
\hline Soomekeelne värvinimetus & Eestikeelne värvinimetus \\
\hline violetti & lilla, violett \\
\hline liila & helelilla, sirelililla \\
\hline kretliini & lilla, tumelilla, sinakaslilla \\
\hline sinipunainen & lilla \\
\hline vaaleanpunainen & roosa \\
\hline pinkki & lillakasroosa, tumeroosa, erkroosa \\
\hline roosa & roosa, lõheroosa, kahvaturoosa \\
\hline aniliini & punakaslilla, erkroosa \\
\hline purppura & lillakaspunane, punakaslilla \\
\hline
\end{tabular}

\section{Viidatud kirjandus}

Davies, Ian; Corbett, Greville 1995. A practical field method for identifying probable basic colour terms. - Languages of the World, 9, 25-36.

EKSS $=$ Eesti kirjakeele seletussõnaraamat I-VI. Eesti Keele Instituut. Tallinn: Eesti Keele Sihtasutus, 2009.

Ganander, Chrisfrid 1997. Nyt finskt lexicon. Alkuperäiskäsikirjoituksesta [1786-1787] toimittanut Liisa Nuutinen. Suomalaisen Kirjallisuuden Seuran toimituksia, 676. Kotimaisten kielten tutkimuskeskuksen julkaisuja, 95. Helsinki: Suomalaisen Kirjallisuuden Seura, Kotimaisten kielten tutkimuskeskus.

Hellquist, Elof 1922. Svensk etymologisk ordbok. Lund: Gleerups.

Kerttula, Seija 2007. Relative basicness of color terms: Modeling and measurement. - Robert E. MacLaury, Galina V. Paramei, Don Dedrick (Eds.). Anthropology of Color. Interdistiplinary multilevel modeling. Amsterdam, Philadelphia: John Benjamins, 151-169.

Kornerup, Andreas; Wanscher, Johan Henrik 1961. Värien kirja. Kaarle Hirvonen (toim.). Porvoo: WSOY.

Koski, Mauno 1983. Värien nimitykset suomessa ja lähisukukielissä. Suomalaisen Kirjallisuuden Seuran toimituksia, 391. Helsinki: Suomalaisen Kirjallisuuden Seura.

Must, Mari 2000. Vene laensõnad eesti murretes. Tallinn: Eesti Keele Sihtasutus.

Mägiste, Julius 1982-1983. Estnisches etymologisches Wörterbuch. Helsinki: FinnischUgrische Gesellschaft.

NS = Nykysuomen sanakirja. Porvoo, Helsinki: Suomalaisen Kirjallisuuden Seura, Werner Söderström osakeyhtiö, 1951-1961.

Oja, Vilja 2001. Linguistic studies of Estonian colour terminology. Dissertationes philologiae estonicae Universitatis Tartuensis, 9. Tartu: Tartu University Press.

Oja, Vilja 2002. Some semantic problems in the translation of colour terms. - Henrik Gottlieb, Jens Erik Mogensen, Arne Zettersten (Eds.). Symposium on Lexicography $\mathrm{X}$. Proceedings of the Tenth International Symposium on Lexicography May 4-6, 2000, at the University of Copenhagen. Lexicographica. Series Maior, 109. Tübingen: Niemeyer, 253-260. 
Oja, Vilja 2007. Colour naming in Estonian and cognate languages. - Robert E. MacLaury, Galina V. Paramei, Don Dedrick (Eds.). Anthropology of Color. Interdistiplinary multilevel modeling. Amsterdam, Philadelphia: John Benjamins, 189-209.

PS = Suomen kielen perussanakirja. Kotimaisten kielten tutkimuskeskuksen julkaisuja, 55 . Helsinki: Edita, Kotimaisten kielten tutkimuskeskus, 1990-1994.

SSA = Suomen sanojen alkuperä. Etymologinen sanakirja. Suomalaisen Kirjallisuuden Seuran toimituksia, 556. Kotimaisten kielten tutkimuskeskuksen julkaisuja, 62. Helsinki: Suomalaisen Kirjallisuuden Seura, Kotimaisten kielten tutkimuskeskus, 1992-2000.

Sutrop, Urmas 1995. Eesti keele põhivärvinimed. - Keel ja Kirjandus, 12, 797-808.

Sutrop, Urmas 2002. The vocabulary of sense perception in Estonian: Structure and history. Opuscula Fenno-Ugrica Gottingensia, 8. Frankfurt am Main: Peter Lang.

Uusküla, Mari 2007. The basic colour terms of Finnish. - SKY Journal of Linguistics, 20, 367-397.

Uusküla, Mari 2008. Basic colour terms in Finno-Ugric and Slavonic languages: Myths and facts. Dissertationes linguisticae Universitatis Tartuensis, 9. Tartu: Tartu University Press.

Uusküla, Mari 2009. Some remarks on colour naming differences in Finnish. - Marja Kallasmaa, Vilja Oja (toim.). Kodukeel ja keele kodu. Home language and the home of a language. Pühendusteos Helmi Neetarile 75. sünnipäevaks 29. jaanuaril 2009. Eesti Keele Instituudi toimetised, 13. Tallinn: Eesti Keele Sihtasutus, 265-272.

Wiedemann, Ferdinand Johann 1973. Eesti-saksa sõnaraamat. Estnisch-deutsches Wörterbuch. Neljas, muutmata trükk teisest, Jakob Hurda redigeeritud väljaandest. Vierter unveränderter Druck nach der zweiten, von J. Hurt redigierten Auflage [1893]. Tallinn: Valgus.

Vilja Oja (Eesti Keele Instituut) peamised uurimisvaldkonnad on dialektoloogia, leksikoloogia, geolingvistika, soome-ugri keeled, läänemeresoome keelte vastastikused suhted ja keelekontaktid. vilja.oja@eki.ee

Mari Uusküla (Eesti Keele Instituut) peamised uurimisvaldkonnad on värvinimed, võrdlev leksikoloogia, soome-ugri keeled ja antropoloogiline lingvistika.

mari.uuskyla@eki.ee 


\title{
ON SOME COLOUR TERMS AND THEIR SEMANTIC RELATIONSHIPS IN ESTONIAN AND FINNISH
}

\author{
Vilja Oja, Mari Uusküla
}

Institute of the Estonian Language

The article discusses the terms for hues from purple to pink used in spoken Estonian and spoken Finnish. Most of the dialectal material illustrates the usage of the first half of the 2oth century, while the results of the field work conducted in the 1990s and 2005-2006 are treated as indicative of the modern state of the art. In Estonian as well as in Finnish, both purple and pink have been referred to by words for the main hue (blue or red) or by their combinations, or by comparison-based compound terms.

Beside those there are a number of borrowed terms with Indo-European stems, such as lilla, violett, maliina, aniliin, purpur, kretliini, roosa and pinkki. With the help of the native speakers, the part of the spectrum area or concrete hue referred to by this or that term has now been specified. It turns out that the use of the terms borrowed from Indo-European languages differs, on the one hand, from that of the donor language and, on the other hand, across the languages/dialects spoken in the Finnic area. In addition, our lexical comparison revealed the changes in reference to the colour concepts in question over the past century. Among else, there is a clear tendency towards an increasing preference of borrowed terms.

Keywords: colour terms, pink, purple, spoken language, dialect speech, Estonian, Finnish 